\title{
O LUGAR DAS TEORIAS LINGUÍSTICAS NO VESTIBULAR
}

\author{
Erislane Rodrigues Ribeiro
}

\begin{abstract}
RESUMO
Neste trabalho, com o objetivo de avaliar qual é o lugar ocupado pelas teorias linguísticas no vestibular, à luz de trabalhos de pesquisadores brasileiros preocupados com a aplicação das teorias linguísticas ao ensino, são realizadas análises de manuais do candidato ao vestibular da UFG, as quais revelam um alinhamento dos mesmos às disciplinas da Linguística em destaque no período da publicação.
\end{abstract}

PALAVRAS-CHAVE: teorias linguísticas; vestibular; manual do candidato.

\section{Introdução}

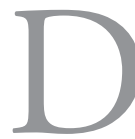

entre as reflexôes que acompanham o homem ao longo de sua existência, destacam-se a sua preocupação em compreender o fenômeno da linguagem e a necessidade de descrever e analisar as línguas, o que resultou na realização de diversos estudos que, antecedendo o que veio a se constituir em uma ciência voltada para este fim, a Linguística, fundada no século XX pelo linguista genebrino Saussure, contribuíram significativamente para fazer avançar as pesquisas relacionadas a estes temas, sob perspectivas as mais variadas, como a filosófica, a filológica, a retórica, a da gramática tradicional, dentre outras.

A despeito de se reconhecer a importância de estudos realizados sobre a linguagem e as línguas antes da publicação do Curso de linguistica geral, não se pode questionar que os estudos linguísticos avançaram sobremaneira quando 
se passaram a definir melhor as teorias e as metodologias para o estudo de seus objetos. Tais avanços podem ser observados frequentemente no Brasil, tanto em publicações como em apresentações de pesquisas em eventos científicos concernentes às variadas disciplinas da Linguística.

Entretanto, não é apenas nos livros especializados e em eventos científicos que se podem observar o lugar e o desenvolvimento das teorias linguísticas. Os livros didáticos de Português e certos documentos institucionais, por exemplo, são um rico material, cuja análise pode revelar bastante acerca da história e da repercussão dos estudos linguísticos no Brasil.

Neste artigo, o objetivo principal é investigar como algumas das contribuiçôes de diversas disciplinas da Linguística influenciaram o que se propôs para as provas de Língua portuguesa e Redação do vestibular da UFG ao longo do tempo. Com isso, simultaneamente, identificam-se quais e por que razóes tendências teóricas da linguística sobressaíram em dado momento sócio-histórico. Para tal, são analisados manuais do candidato da UFG publicados entre os anos de 1975 e 2011.

Os manuais do candidato são analisados, nesta pesquisa, sob a ótica de pesquisadores tais como Mendonça (2006), Soares (2002) e Gregolin (2007). Adotou-se uma metodologia em que foram agrupados manuais por períodos sócio-históricos, pois em tais períodos não se observam mudanças significativas com relação às teorias linguísticas que os subsidiam. Assim, os textos componentes do corpus são analisados, seguindo-se a seguinte periodicidade: de 1975 a 1986; de 1987 a 1990; de 1991 a 1994; de 1995 a 2003 e de 2004 a 2011; por fim, apresentam-se as considerações finais e as referências bibliográficas.

\section{De 1975 a 1986: a vez da gramática normativa, da retórica, da poética e da teoria da comunicação}

De 1975 a 1986, os programas para a prova de língua portuguesa permaneceram praticamente inalterados. Constavam do programa da UFG (1975) os seguintes conteúdos: estrutura e formação das palavras portuguesas, substantivo, adjetivo, pronome, verbo, preposição, conjunção, advérbio, estrutura da frase, concordância nominal e verbal, regência nominal e verbal, colocação das palavras na frase, principais figuras de estilo, sinônimos, antônimos e parônimos, conotação e denotação, ortografia e pontuação. 
No programa para a prova discursiva de língua portuguesa do vestibular da UFG para o ano de 1975, observa-se que a ênfase é dada aos conteúdos gramaticais, seguidos por tópicos de estilística, tais como principais figuras de estilo, conotação e denotação, o que revela que a UFG acompanhava o que predominava no âmbito dos objetivos do ensino de português, pois, conforme afirma Soares (2002, p. 168), desde a reforma proposta por Marquês de Pombal nos anos 50 do século XVIII até o final do século XIX, estudava-se a língua portuguesa através de "dois conteúdos, que hoje denominaríamos 'disciplinas curriculares': gramática e retórica”. No início a poética, a qual tinha por objetivo "o estudo da poesia, das regras de métrica e versificação dos gêneros literários, da avaliação da obra literária, enfim, daquilo a que hoje chamaríamos literatura ou teoria da literatura”, era incluída na retórica, cujas finalidades eram relativas "à arte de falar bem, à arte de elaboração dos discursos, à arte da elocução" (SOARES, 2002, p. 168). Mais tarde, as duas disciplinas desvincularam-se, tornando-se disciplinas diferentes.

No programa da prova discursiva de língua portuguesa para o ano de 1975, havia uma quantidade de tópicos relacionados aos estudos gramaticais bem maior do que aqueles relativos ao que hoje se denomina literatura. A principal razão para esse fato talvez esteja na força da tradição que remonta ao tempo dos jesuítas e continua ao longo dos séculos, persistindo em diversos espaços até os dias de hoje.

Aos conteúdos constantes no programa de 1975, foram acrescentados, em 1976, os seguintes: acentuação vocabular, fonemas e gramemas, divisão silábica, o esquema da comunicação (emissor, receptor, mensagem; o canal da comunicação, o referente, codificação e decodificação, o signo - código escrito e oral) e os níveis de linguagem. Assim permaneceu até 1979. Desta forma, aos conteúdos de gramática já existentes, relativos especialmente à morfologia e à sintaxe, foram acrescentados outros, vinculados à fonética e à fonologia principalmente. Além disso, uma importante mudança ocorreu com o acréscimo do esquema da comunicação como conteúdo da prova de língua portuguesa.

Em 1971, a nova Lei de Diretrizes e Bases da Educação (Lei 5692/ 71) já dava indícios de que a teoria da comunicação havia ultrapassado os limites das Universidades. Como descreve Soares (2002, p. 168), a nova lei alterou a denominação da disciplina português para "comunicação e expressão nas séries iniciais do então criado $1^{\circ}$ grau, e comunicação em língua portuguesa, nas séries 
finais desse grau; só no $2 \mathbf{0}$ grau o foco em 'comunicação' desaparece da denominação que, nesse grau, passa a ser Lingua portuguesa e Literatura brasileira”.

Tanto a alteração do nome da disciplina português para comunicaçáo e expressão e comunicação em língua portuguesa como também a inclusão do esquema da comunicação no programa do vestibular da UFG decorreram do surgimento da teoria da comunicação, "como quadro referencial para a análise da língua, transposta da área dos meios eletrônicos de comunicação" (SOARES, 2002, p. 168).

$\mathrm{Na}$ década de 70 e início da década de 80 , era comum o manual do candidato apresentar uma bibliografia referente a cada prova do vestibular. Além das obras literárias indicadas como leitura obrigatória e obras de teoria e história da literatura, incluiu-se, de 1975 a 1977, a sugestão da leitura de Cunha (1975) e de Mattos (1974). Além desses, de 1978 a 1982 acrescentou-se a obra de Garcia (1967).

A partir de 1980, o programa foi dividido em dois subitens. Do primeiro, denominado língua portuguesa, faziam parte os seguintes temas: estrutura e formação das palavras portuguesas, substantivo, adjetivo, pronome, verbo, preposição, conjunção, advérbio, estrutura da frase, concordância nominal e verbal, regência nominal e verbal, colocação das palavras na frase, acentuação vocabular, ortografia e pontuação, fonemas e gramemas e divisão silábica; do item intitulado análise e interpretação de textos (literários e não-literários) constavam: as principais figuras de estilo, sinônimos, antônimos e parônimos, conotação e denotação, o esquema da comunicação (emissor, receptor, mensagem; o canal da comunicação, o referente, codificação e decodificação, o signo - código escrito e oral) e os níveis de linguagem. Com exceção do fato de que, a partir de 1980, os conteúdos passaram a vir divididos entre os itens citados, podemos concluir que, de 1976 a 1986, o programa para a prova de língua portuguesa permaneceu praticamente intocado.

$\mathrm{Na}$ década de 80 , permaneceu a prática de se incluírem bibliografias aos programas das disciplinas. No caso das áreas de língua portuguesa, redação e literatura, a bibliografia passou a ser dividida em duas partes; uma com a indicação de gramáticas e outra com obras das áreas de redação e literatura. De 1983 a 1986, além da gramática de Cunha; Cintra (1975), foram indicadas as de Bechara (1988), Cegalla (1993), Cunha (1970), Rocha Lima (1972), Sacconi (1999), Santos [19--] e Bueno (1968). Na área de redação, além do livro 
de Garcia (1967), foram recomendadas as obras de Brait; Negrini; Lourenço (1977), Marino (1980), Meserani; Kato (1979), Mattos (1974), Leme et ali (1981), Mattos [19--?], Macedo (1976), Melo (1978), Soares; Campos (1978).

Nesses quatros anos, o número de gramáticas e de obras didáticas voltadas para o segundo grau indicadas cresceu consideravelmente, graças ao aumento gradativo da sua publicação no cenário das editoras brasileiras. Além disso, os manuais de redação passaram a ter um papel de destaque na bibliografia do programa de língua portuguesa, com a inclusão das provas de redação e das provas discursivas no vestibular da UFG.

\section{De 1987 a 1990: o contraditório em pauta: gramática normativa x sociolinguística}

De 1987 a 1990, os conteúdos continuaram a ser distribuídos em duas partes distintas: estudo de texto e gramática. A primeira parte tinha como objetivo "avaliar a capacidade de o candidato compreender adequadamente textos literários e não- - literários", segundo os seguintes itens: "usos da linguagem, as variedades linguísticas; sentido literal e sentido figurado (denotação e conotação); figuras de linguagem: metáfora e metonímia; idéias principais do texto; inter-relaçóes das partes do texto; o sentido contextual de palavras, expressóes, períodos e parágrafos; resumo de parágrafos e do texto; interpretação crítica e coerente do texto". Com a gramática, objetivava-se "avaliar a capacidade de reflexão do candidato sobre os fatos comuns da língua de cultura do Brasil e sua habilidade em depreender o valor e a função das formas linguísticas”. Os conteúdos dessa parte do programa eram: estrutura e formação de palavras; as classes de palavras, com exceção das interjeições; a estrutura da frase: coordenação e subordinação entre termos oracionais e entre oraçóes; sintaxe de regência, concordância e colocação; pontuação (UFG, 1990).

Como se vê, mantêm-se, de 1987 a 1990, praticamente os mesmos tópicos relativos à gramática, bem como certos temas da estilística e da teoria da literatura, apresentados pelos manuais nos anos anteriores. Entretanto, excluiu-se o esquema da comunicação, provavelmente em razão dos "duvidosos resultados que ela trouxe para a aprendizagem da língua", o que fez, inclusive, com que fossem "eliminadas as denominaçóes comunicação e expressão e comunicação em língua portuguesa, e recuperada a denominação português [...]" (SOARES, 2002, p. 170). 
Além disso, em decorrência da introdução da sociolinguística nos currículos de formação de professores, o vestibular da UFG incluiu como conteúdo do programa de língua portuguesa "as variedades linguísticas". Nesse período, estudos sob a perspectiva da teoria da variação linguística, sob a influência de Labov, vinham sendo realizados no Brasil. Fernando Tarallo é comumente citado como uma das primeiras referências da área, tendo publicado, em 1985, A pesquisa sociolinguistica, "em que divulga, além dos resultados de uma pesquisa sua sobre aspectos sintáticos do português do Brasil, a metodologia de trabalho de Labov, os resultados de alguns dos trabalhos desse lingüista e os pressupostos que subjazem a essas pesquisas" (SOARES, 2002, p. 160).

Além de Tarallo, uma pesquisadora que realizou um importante trabalho ao elaborar uma proposta para o ensino de português com base em pressupostos labovianos foi Soares (1994) que, com a publicação de seu Linguagem e escola: uma perspectiva social, o qual teve uma aceitação ímpar em cursos superiores, em especial Letras e Pedagogia, acirrou o debate sobre a importância de se considerar as variedades linguísticas dos alunos.

No período de 1987 a 1990, a bibliografia das áreas de língua portuguesa, redação e literatura foi unificada, com o título "literatura brasileira". Excluídas as obras de teoria literária, constavam da lista as gramáticas de Bechara (1988), Cegalla (1993), Cunha; Cintra (1975), Savioli (1984), além dos livros voltados à redação de Soares; Campos (1978) e Gorki.

Como vemos, de 1987 a 1990 houve uma diminuição no número de gramáticas indicadas e foram excluídas as obras didáticas destinadas ao ensino de segundo grau. Além das gramáticas, foram sugeridos dois livros com orientaçóes para a produção da escrita. Apesar de ter permanecido a inclusão das variações linguísticas como conteúdo da prova de língua portuguesa, não foi indicada nenhuma obra que tratasse especificamente do tema.

\section{1991 a 1994: a influência da linguística textual}

Em relação aos manuais anteriores, em 1991 e 1992 excluíram-se, da parte denominada estudo do texto, os conteúdos: níveis de linguagem, inter-relaçóes das partes do texto, interpretação crítica e coerente do texto; e foram acrescentados os itens: organização das ideias: relaçóes lógicas entre as ideias, unidade e coerência do texto; associação da palavra à imagem: interpretação 
de quadrinhos, publicidade, fotografia. Quanto à parte da gramática, os conteúdos permaneceram inalterados, com a observação de que, por meio da análise de textos, é que seriam avaliados os conhecimentos gramaticais dos candidatos, ou melhor, "a compreensão e o domínio (reconhecimento e uso adequado) das estruturas da língua portuguesa”.

Destaca-se aqui que, apesar de não constar mais no programa a teoria da comunicação, ainda como ressonância de sua aplicação à análise e estudo da língua portuguesa, são incluídos gêneros como fotografia e quadrinhos para serem interpretados, revelando, ainda, uma mudança em relação aos critérios para a seleção dos textos, não apenas literários, mas, sobretudo,

por critérios de intensidade de sua presença nas práticas sociais: textos de jornais e revistas, histórias em quadrinhos, publicidade, humor passam a conviver com os textos literários; amplia-se, assim, o conceito de 'leitura': não só a recepção e interpretação do texto verbal, mas também do texto não-verbal [...]" (UFG, 1992).

Nas orientaçôes aos candidatos, com a inclusão do item "associação da palavra à imagem: interpretação de quadrinhos, publicidade, fotografia”, observa-se a manutenção do conceito de língua como comunicação. Com essa concepção de linguagem, como ressalta Soares (2002), pressupóe-se que, na escola, os objetivos com o ensino de português deveriam passar a ser pragmáticos e utilitários.

trata-se de desenvolver e aperfeiçoar os comportamentos do aluno como emissor e recebedor de mensagens, através da utilização e compreensão de códigos diversos - verbais e nãoverbais. Ou seja, já não se trata mais de estudo sobre a língua ou de estudo da língua, mas de desenvolvimento do uso da língua (SOARES, 2002, 169).

Com a substituição da concepção de língua como sistema que, segundo Soares (2002, p. 169), prevalecia “até então no ensino da gramática, e a concepção da língua como expressão estética, prevalente inicialmente no ensino 
da retórica e da poética e, posteriormente, no estudo de textos" pela concepção de língua como forma de comunicação, altera-se a abordagem da gramática. Segundo a UFG (1991-1992), em seu processo seletivo, conhecimentos gramaticais serão exigidos do candidato. No entanto, o candidato precisar demonstrar sua "compreensão e o domínio (reconhecimento e uso adequado) das estruturas da língua portuguesa" ao analisar textos.

Destacamos, também, que os itens: "organização das ideias: relações lógicas entre as ideias, unidade e coerência do texto" evidenciam aquilo de que trata Soares em relação à contribuição da linguística textual, a qual vem, nas palavras da autora, "ampliar essa nova concepção da função e natureza da gramática para fins didáticos, evidenciando a necessidade e conveniência de que essa gramática [...] chegue ao texto” (UFG, 1991-1992).

Para os vestibulares de 1991 e 1992, a bibliografia sugerida foi composta pelas gramáticas de Bechara (1988), Cunha; Cintra (1985), além dos livros de Rosa; Nogueira (1976), Scarton; Del Pino (1987), Barbosa; Amaral (1991), Soares; Campos (1978) e Cagnin (1975). Dentre as obras indicadas, o que mais chama a atenção é a inclusão do livro Os quadrinhos de Cagnin (1975), em decorrência do espaço que teorias sobre os textos começam a assumir na área de Letras e no ensino de português.

Nos anos seguintes, 1993 e 1994, o programa de língua portuguesa não foi alterado. Porém, a bibliografia passou por mudanças. Mantiveram-se as gramáticas de Bechara (1988) e Cunha; Cintra (1985), além dos livros de Rosa; Nogueira (1976), Scarton; Del Pino (1987), Barbosa; Amaral (1991), Soares; Campos (1978). Além desses, foram acrescentadas as obras de Bibe-Luyten, Fiorin; Savioli (1993), Koch; Travaglia (1993) e Koch; Travaglia (1995).

Nesses dois anos, o que mais chama a atenção e merece uma reflexão é a inclusão das obras de Fiorin; Savioli (1993) e Koch; Travaglia (1993) e Koch; Travaglia (1995). Conforme ressalta Mendonça (2006, p. 150), muitas obras publicadas no Brasil nas décadas de 1980 e 1990 já "apontavam o texto ora como elemento central nas aulas de língua, ora como objeto de estudo pela lingüística”. A autora dá, assim, pistas a partir das quais pode ser justificada a inclusão das obras citadas acima na bibliografia sugerida aos vestibulandos. Apesar de as duas últimas obras citadas possuírem um caráter teórico e a primeira fins didáticos, já que os autores desta têm por finalidade básica "auxiliar o aluno a tornar-se um leitor autônomo e um produtor competente de textos" 
(FIORIN; SAVIOLI, 1993, p. 3), as três obras têm em comum, como principal preocupação, o texto.

\section{1995 a 2003: as primeiras contribuições dos estudos enunciativos e discursivos}

Em 1995, o manual do candidato passou por profundas transformaçóes em relação ao conteúdo programático de língua portuguesa e não houve indicação bibliográfica. De 1996 a 1998, continuaram sendo indicados para as provas de língua portuguesa a gramática de Cunha; Cintra (1985) e o livro de Fiorin; Savioli (1993). Além desses, foram sugeridos pela primeira vez os livros de Citelli (1994) e de Faraco; Tezza (1992). O livro de Citelli (1994), apesar de não ser um livro com fins didáticos, tem por objetivo complementar o ensino de $1^{\circ}$ e $2^{\circ}$ graus. Sua inclusão na bibliografia sugerida pela UFG se deve, provavelmente, à ênfase dada nas provas discursivas e na prova de redação aos textos argumentativos. A partir de 1999, com exceção de algumas obras literárias indicadas como leitura obrigatória, não foram mais sugeridas fontes bibliográficas (teóricas) específicas para as áreas de língua portuguesa, literatura e redação.

Nos manuais anteriores a 1995, o que se fazia era quase que simplesmente listar os conteúdos que poderiam vir a ser tema das provas do vestibular da UFG. Nos manuais distribuídos aos candidatos de 1995 em diante, a UFG (1995-2003) apresentou, como programa de literatura brasileira e língua portuguesa, um texto contendo uma nova proposta: ao invés de listar conteúdos, apresentou aos candidatos qual era a concepção de linguagem adotada em seu processo seletivo e o que, em decorrência dessa concepção, se esperava deles quanto à leitura, à produção de textos, incluindo aqui a redação, e à gramática.

Nesse texto, inicialmente destaca-se a importância da linguagem, considerando que seu uso adequado é essencial não apenas para o desempenho acadêmico e profissional dos indivíduos, como também nas mais diversas situaçôes, posto que está presente na maioria das atividades humanas, com sua "multiplicidade de modalidades, usos e funçôes". Em seguida, a linguagem (oral e escrita) é apresentada como uma "atividade social que nos possibilita interagir com outras pessoas de nossa convivência direta ou indireta”. Segundo 
essa concepção, os sentidos dos enunciados são produzidos e compreendidos, pelos interlocutores, no processo de interação (UFG, 2003).

Percebe-se, pela leitura desse manual, que ele se encontra em consonância com o valor que os Parâmetros Curriculares Nacionais atribuem ao uso da escrita e fala. Segundo os PCNs, uma das finalidades de se ensinar língua portuguesa no ensino fundamental brasileiro é

utilizar a linguagem na escuta e produção de textos orais e na leitura e produção de textos escritos de modo a atender a múltiplas demandas sociais, responder a diferentes propósitos comunicativos e expressivos, e considerar as diferentes condições de produção do discurso (BRASIL, 1997).

Em conformidade com uma concepção de linguagem como forma de interação, nas provas de língua portuguesa da UFG, segundo a instituição, o objeto de trabalho é "o texto e/ou discurso, vistos aqui como uma unidade de linguagem significativa em uso". Nesse contexto, "as situaçóes de uso", quer dizer, "a informação contextual" têm um papel relevante, pois considera-se importante, nas atividades de leitura e escrita, identificar: "quem fala o quê para quem, onde, quando e com que intençóes?". Além dessas informações contextuais, tem papel de destaque o contexto sócio-cultural, já que também contribui na produção dos sentidos e "delimita os conhecimentos partilhados pelos interlocutores". Diante disso, os temas selecionados para comporem as provas não se distanciarão do universo sócio-cultural dos candidatos, além do que os textos escolhidos para a elaboraçáo das provas serão variados, pertencendo a gêneros diversos, com as mais diferentes funçôes (UFG, 2003).

Essas diversas e significativas alteraçóes ocorridas no manual do candidato da UFG decorrem, certamente, da influência que

vem sendo exercida sobre a disciplina português concomitantemente pela pragmática, pela teoria da enunciação, pela análise do discurso; influência fundamental, porque traz, basicamente, uma nova concepção de língua: uma concepção que vê a língua como enunciação, não apenas como comunicação, que, portanto, inclui as relaçóes da língua com 
aqueles que a utilizam, com o contexto em que é utilizada, com as condiçôes sociais e históricas de sua utilização" (UFG, 2002).

Veja-se, agora, o que, pela análise do manual, pode-se depreender em relação ao que se espera dos candidatos quanto à leitura, à escrita e à gramática. A leitura é entendida não como "uma tarefa mecânica de decodificação". Trata-se, segundo a UFG (2003), de "um processo ativo de construção de sentidos". Sob esse ponto de vista, "o sentido não está somente na mensagem escrita”, mas é construído pela interação do leitor com o texto. Então, se da relação leitor-texto constrói-se o sentido dos textos, isso significa que "diferentes leitores podem produzir leituras diferentes do mesmo texto", o que não é o mesmo que dizer que um texto admite qualquer leitura. $\mathrm{O}$ candidato revelará ser um leitor eficiente caso seja capaz de reconstruir os diversos sentidos do texto (reconhecendo recursos como o da intertextualidade, por exemplo), bem como desenvolver inferências que o levem a uma postura crítica e reflexiva diante do mundo (UFG, 2003).

Considerado fator essencial para o aluno de terceiro grau, o domínio da argumentação escrita é avaliado, prioritariamente, segundo a UFG, na prova de redação. Tal avaliação, seja na redação ou na prova discursiva de língua portuguesa, recai, especialmente, na capacidade dos candidatos em "pensar por escrito, organizando as ideias, estabelecendo relaçóes, interpretando dados e fatos, elaborando hipóteses", utilizando "adequadamente os recursos lingüísticos na produção de um texto” (UFG, 2003).

A despeito da relação entre leitura e escrita, a UFG ressalta que a qualidade da leitura é fundamental para uma boa escrita e que o que se espera do candidato é que "mostre a capacidade de leitura necessária para apreender a ideia-núcleo dos textos apresentados”, para, a partir dela, produzir o seu texto escrito (UFG, 2003).

Conforme a UFG, quanto à apreensão dos recursos linguísticos no momento da leitura, os candidatos serão avaliados quanto à maneira como agem sobre o texto em sua totalidade, "reconhecendo como são articulados seus elementos linguísticos, a fim de constituir um todo significativo. O que importa é avaliar o efeito de sentido dos recursos linguísticos”. Desse modo, quando das orientaçóes em relação à gramática, enfatiza-se que o importante é a competência gramatical como um dos vários componentes que se utili- 
zam no processo de produção e compreensão dos sentidos. Com isso, a UFG (2003) revela o propósito de mudar os "objetivos em relação às provas de Língua Portuguesa", porque "mais do que um conhecimento explícito de uma nomenclatura relativa às unidades frasais e sua convencionalização em regras gramaticais, o que está em jogo é a sua competência para utilizar esse conhecimento nas diversas situações em que for requerido o uso da nossa língua". Segundo o manual "torna-se necessário não nos limitarmos à análise de frases, mas considerar, também, as relaçóes entre a língua e seus usuários”, por isso, em lugar de analisar unidades isoladas (frases e palavras), o candidato "deverá demonstrar a capacidade de ler e escrever textos ligados a contextos sociais, relacioná-los e perceber a sua pertinência” (UFG, 2003).

Esta proposta de substituição da "supervalorização de estudo da metalinguagem gramatical presente nas gramáticas tradicionais, direcionando o trabalho gramatical a ser realizado na sala de aula para os aspectos observados no uso linguístico dos alunos", conforme destaca Mendonça (2006), também é defendida, segundo a autora, nos PCNs de 1997.

\section{2004 a 2011: a crescente influência da análise do discurso}

Em 2004, resultado de "ampla discussão envolvendo os coordenadores de todos os cursos de graduação", foi traçado o perfil e as habilidades gerais esperados do egresso do ensino médio para ingresso na UFG. "Esse procedimento teve por objetivo subsidiar a reconstrução do modelo do processo seletivo da UFG. A proposta do processo seletivo de 2004 é resultante, dentre outras referências, do perfil e habilidades gerais" (UFG, 2004).

Como no modelo anterior (1995-2003), para os processos seletivos ocorridos a partir de 2004 (2004-2011), apresenta-se um texto, com informaçóes aos candidatos sobre o modo como a UFG concebe a linguagem e sobre o que espera deles no momento da avaliação em língua portuguesa. Assim como no manual de 2003, a concepção de linguagem apresentada pela UFG é aquela em que a linguagem (oral e escrita) é vista como tendo caráter essencialmente social e interativo. Reconhecendo o aspecto social da linguagem, as situaçóes comunicativas de utilização da língua e o contexto sociocultural de cada situação específica adquirem um papel decisivo tanto na produção como na compreensão dos textos. Segundo a UFG, o candida- 
to é considerado um produtor de texto, sendo este entendido como "a unidade básica da linguagem verbal e da análise da língua. [...] produto de uma história social e cultural, constituído pelos interlocutores que o produzem” (UFG, 2004).

Para a construção de seus textos e a produção de sentidos, o vestibulando é orientado a considerar os seus interlocutores, o papel deles naquela esfera específica, o tema em questão, o gênero textual utilizado, o lugar e o momento da interação. Concebida a leitura como um processo ativo em que os sentidos são construídos, espera-se que os candidatos percebam como os elementos linguísticos encontram-se articulados num texto, com a finalidade de reconstruir o efeito de sentido criado pelo locutor. Além disso, apresenta-se a ideia de que tão importante como perceber que o sentido é construído por meio da interação entre o leitor e o texto, é reconhecer o diálogo que se estabelece entre os textos e que os mesmos podem pertencer a gêneros diversos, com as mais variadas funções. O sucesso ou o fracasso no uso da língua, nessa perspectiva, depende do modo como se escreve, se desta ou daquela forma, de acordo esse ou com aquele gênero (UFG, 2004-2008).

Assim, a avaliação da escrita no processo seletivo leva em consideração não apenas a capacidade dos candidatos em usar os recursos linguísticos na produção de um texto, como também a sua competência em reconhecer que o uso depende do "conhecimento sobre o dito/escrito, a escolha de gêneros e de tipos de discurso". Além disso, as escolhas realizadas pelos vestibulandos no momento da prova acabam por refletir, segundo a UFG, o conhecimento e domínio (ou a falta de conhecimento e domínio) de "estratégias textuais, que são declaradas e que também ficam implícitas” (UFG, 2004-2008).

Em comparação com o manual dos anos anteriores, destaca-se a ênfase dada ao dialogismo e aos gêneros do discurso nos manuais deste período. Desse modo, a UFG, em determinados momentos, parece alinhar seu discurso à concepção dialógica da linguagem bakhtiniana, já que o autor russo é a principal referência quando se fala em dialogismo e em gêneros. Para Bakhtin, todo enunciado é dialógico, sendo o dialogismo o modo de funcionamento real da linguagem; quanto aos gêneros, segundo ele, a escolha que se faz deles "é determinada em função da especificidade de uma dada esfera da comunicação verbal, das necessidades de uma temática (do objeto do sentido), do conjunto constituído dos parceiros, etc.". 
Em relação à gramática, seu estudo é visto pela UFG (2004-2008) como "uma estratégia para compreensão/interpretação/produção de textos".

Como se pôde observar, nos últimos anos, tem se acentuado a influência da análise do discurso. Conforme destaca Gregolin (2007),

com as formulaçôes da análise do discurso e a (re)descoberta de Bakhtin, aliamos a ele [texto] o discurso no ensino de língua, acrescentando, assim, à textualidade, a ideia de que os textos são produzidos por interlocutores situados histórica e socialmente, de que os discursos veiculam os valores, as ideologias de uma sociedade. Produzir sentidos é, então, ocupar uma posição, tornar-se sujeito de um dizer frente a outras vozes (GREGOLIN, 2007, p. 69).

As ressonâncias dessas teorias nos manuais do candidato, apesar de poderem ser observadas já entre os anos 1995 e 2003, acentuam-se a partir de 2004, fortalecendo-se a cada ano e a cada novo manual publicado. Veja-se, por exemplo, o trecho que segue, extraído do manual de 2011, o qual se relaciona diretamente ao que afirma Gregolin:

O candidato deve mostrar habilidade de atuar por meio da linguagem escrita, selecionando e articulando recursos linguísticos adequados para produzir os efeitos de sentido desejados para o tipo de interação contemplado pelo gênero, considerando-se os propósitos comunicativos do locutor em relação a um determinado interlocutor, o lugar e o momento da situação comunicativa (UFG, 2011)

\section{Considerações finais}

A Linguística, constituída como ciência a partir de Saussure, desenvolveu-se muito nas últimas décadas. De ciência recém-fundada, tornou-se, rapidamente e por uma razoável fração de tempo, em ciência-piloto das ciências humanas, e hoje, mesmo não ocupando mais um lugar de tanto destaque, continua amealhando milhares de adeptos e simpatizantes. Nas suas mais diversas 
disciplinas têm sido feitas pesquisas relevantes para o avanço dos estudos linguísticos, as quais, para além de representarem a contribuição dos pesquisadores brasileiros às diversas correntes teóricas, apontam para a sua aplicação nos mais diversos campos.

O estudo aqui apresentado, que por ora se dá por encerrado, apresenta uma série de dados que comprovam como e por que motivaçóes os estudos linguísticos têm sido basilares na formulação dos manuais do candidato disponíveis a todos que se inscreveram no vestibular da UFG de 1975 a 2011 e, certamente, na constituição das provas de Língua Portuguesa e Redação, elaboradas por esta universidade.

Não se pode deixar de admitir que, ao longo de mais de trinta anos, o vestibular da UFG vem servindo de parâmetro para a definição de objetivos e programas para o ensino de Português nas escolas de ensino fundamental e médio das redes pública e privada do estado de Goiás, o que também vem ocorrendo com outras universidades em outros estados do país. Nesse sentido, há que se destacar que a UFG, que já há algumas décadas vem pautando o seu trabalho, no que se refere às orientaçôes aos candidatos sobre as provas de Língua Portuguesa e Redação, no que há de mais recente e moderno em relação ao que se teoriza sobre a linguagem e/ou as línguas em cada período, assume um papel de vanguarda frente a outras universidades que resistiram por mais tempo em aplicar as teorias linguísticas a seus vestibulares.

Há que se observar, porém, que nem sempre a aplicação das teorias linguísticas ocorreu simultaneamente ao auge das disciplinas no meio acadêmico. Entretanto, o descompasso entre o período de maior visibilidade de uma teoria e o momento de sua aplicação, no caso do vestibular da UFG, foi bastante salutar, na medida em que deu margem para que tais estudos se solidificassem.

Ademais, vale ressaltar que o que Soares conclui em relação à constituição do português em disciplina também pode servir para o que ocorre com as provas de língua portuguesa e de redação pela análise dos manuais do candidato ao longo dos anos, pois a constituição tanto de um como de outro, em cada momento da história,

é determinada pela natureza dos conhecimentos sobre a língua entáo disponíveis, pelo nível de desenvolvimento em que se encontrem esses conhecimentos, pela formação dos profissionais 
atuantes na área $[\ldots]$ em que estágio de desenvolvimento se encontram os conhecimentos sobre a língua? Sobre seu ensino? Consequentemente, que aspectos da língua são privilegiados? Que concepção se tem da língua e, portanto, de seu ensino [...] (SOARES, 1994, p. 176)

Por fim, para encerrar esta seção destaca-se, tal como fez Mendonça (2006), que

os discursos dos linguistas, ao longo dessas décadas, influenciaram os rumos da educação no país; a instituição escolar é um lugar para dizer a lingua que esse sujeito conquistou. É certo que isso foi possível pelo contexto histórico-ideológico que predominava na época, mas o fato não descarta os esforços políticos de ação no social promovidos por esses profissionais (2006, p. 171).

\section{Referências}

BAKHTIN, M. Estética da criação verbal. São Paulo: Martins Fontes, 2000.

BARBOSA, S. A.; AMARAL, E. Redação: escrever é desvendar o mundo. Campinas: Papirus, 1991.

BECHARA, E. Moderna gramática portuguesa. São Paulo: Companhia Editora Nacional, 1988.

BIBE-LUYTEN, S. O que é história em quadrinhos? São Paulo: Brasiliense, 1987.

BRAIT, E. R. de O.; NEGRINI, J. L. da C. A.; LOURENÇO, N. R. da P. Encontro com a linguagem: $2^{\circ}$ grau. São Paulo: Atual, 1977.

BRASIL, Secretaria de educação fundamental. Parâmetros curriculares nacionais: lingua portuguesa. Brasília: MEC/SEF, 1997.

BUENO, F. da S. Gramática normativa da língua portuguesa. São Paulo: Saraiva, 1968.

CAGNIN; A. L. Os quadrinhos. São Paulo: Ática, 1975.

CEGALlA, D. P. Novissima gramática da língua portuguesa. São Paulo: Ed. Nacional, 1993. 
CITELLI, A. O texto argumentativo. São Paulo: Scipione, 1994.

CUNHA, C. F. da; CINTRA, L.. Gramática do português contemporâneo. Belo Horizonte: Bernardo Álvares, 1985.

CUNHA, C. F. da. Gramática moderna. Belo Horizonte: Bernardo Álvares, 1970.

FARACO, C. A.; TEZZA, C. Prática de texto: língua portuguesa para estudantes universitários. Petrópolis: Vozes, 1992.

FIORIN, J. L; SAVIOLI. Para entender o texto: leitura e redação. São Paulo: Ática, 1993.

GARCIA, O. M. Comunicação em prosa moderna: aprender a escrever, aprendendo a pensar. Rio de Janeiro: Editora da Fundação Getúlio Vargas, 1967.

GORKI, M. Como aprendi a escrever. Porto Alegre: Mercado Aberto, 1994.

GREGOLIN, Maria do Rosário. O que quer, o que pode esta língua? Teorias linguísticas, ensino de língua e relevância social. In: CORREA, Djane Antonucci (Org.). A relevância social da Linguística: linguagem, teoria e ensino. São Paulo: Parábola Editorial; Ponta Grossa: UEPG, 2007. p. 51-78.

KOCH, I. G. V.; TRAVAGLIA, L. C. A coerência textual. São Paulo: Contexto, 1993.

;__. Texto e coerência. São Paulo: Cortez, 1995.

LEME, O. S. et al. Assim se escreve... Gramática. Assim escreveram... literatura: Brasil-Portugal. São Paulo: EPU, 1981.

MACEDO, J. A. A redação do vestibular. São Paulo: Moderna, 1976.

MARINO, E. R. Estudos de português para o $2^{\circ}$ grau. São Paulo: Brasil, 1980. MATTOS, G. Nossa cultura: português para o $2^{\circ}$ grau. São Paulo: FTD, 1974. [19--?].

. Técnicas de redação em língua portuguesa: $2^{\circ}$ grau. São Paulo: FTD,

MELO, W. de A. A redação instrumental. Rio de Janeiro: Editora Rio, 1978.

MENDONÇA, M. C. A luta pelo direito de dizer a língua: a linguística e o purismo linguístico na passagem do século XX para o século XXI. 2006. $249 \mathrm{f}$. Tese (Doutorado em Linguística)-Instituto de Ciências da Linguagem, Universidade Estadual de Campinas, Campinas, 2006.

MESERANI, S. C.; KATO, M. Linguagem: criatividade. São Paulo: Saraiva, 1979. 
ROCHA LIMA, C. H. da. Gramática normativa da língua portuguesa. Rio de Janeiro: José Olympio, 1972.

ROSA, M. da G. S.; NOGUEIRA, A. X. Cultura, literatura e lingua nacional: segundo grau. São Paulo: Brasil, 1976.

SACCONI, L. A. Nossa gramática: teoria e prática. São Paulo: Atual, 1999.

SANTOS, M. dos. Gramática brasileira da língua portuguesa. São Paulo: FTD, [19--?].

SCARTON, G.; DEL PINO, D. Leitura, lingua e literatura. São Paulo: Saraiva, 1987.

SOARES, M. B. Linguagem e escola: uma perspectiva social. São Paulo: Ática, 1994.

. Português na escola: história de uma disciplina curricular. In: BAGNO, Marcos (Org.). Linguistica da norma. São Paulo: Ediçóes Loyola, 2002. p.155-177.

; CAMPOS, E. N. Técnica de redação: as articulaçóes lingüisticas como técnicas de pensamento. Rio de Janeiro: Ao livro técnico, 1978.

UFG. Comissão especial do concurso vestibular. Manual do candidato: processo seletivo. Goiânia, 1975.

. Manual do candidato: processo seletivo. Goiânia, 1976-1979.

. Manual do candidato: processo seletivo. Goiânia, 1975-1982.

. Manual do candidato: processo seletivo. Goiânia, 1980-1986.

. Manual do candidato: processo seletivo. Goiânia, 1987-1990.

. Manual do candidato: processo seletivo. Goiânia, 1991-1992.

. Manual do candidato: processo seletivo. Goiânia, 1995-2003.

UFG. Centro de seleção. Manual do candidato: processo seletivo. Goiânia, 2003.

. Goiânia, 2004-2008. 


\title{
THE PLACE OF linguistic THEORIES ON VESTIBULAR
}

\author{
ABSTRACT \\ In this work, in order to evaluate which is the place \\ occupied by the vestibular linguistic theories, in the \\ light of work of Brazilian researchers concerned with the \\ application of linguistic theories to teaching, analyzes \\ are books for the entrance exam candidate UFG, which \\ reveal an alignment of the same disciplines of linguistics \\ highlighted in the publication period.
}

KEYWORDS: linguistic theories; vestibular; books for the entrance exam candidate.

Recebido em 30/03/14 Aprovado em 06/07/14 